\title{
Using of Bee Products as Bioindicators in Identifying Toxic Heavy Metal Residues That Causing Environmental Pollution in Sanliurfa Province
}

\author{
Hikmet Dinc (Corresponding author) \\ Faculty of Veterinary Medicine Department of Pharmacology and Toxicology, \\ Harran University, Sanliurfa, Turkey \\ E-Mail: hikmetdnc@gmail.com \\ Muhammed Yasar Dortbudak \\ Faculty of Veterinary Medicine, Fisheries and Diseases Department, \\ Harran University, Sanliurfa, Turkey \\ E-Mail: mydortbudak@gmail.com
}

\begin{abstract}
In this study the concentrations of some elements in 45 honey samples were investigated. Samples were obtained from bee keepers of all the counties of Şanlıurfa province (Center, Bozova, Siverek, Harran, Bozova, Suruç) in 2019. The levels of $\mathrm{Pb}, \mathrm{Cd}, \mathrm{Al}, \mathrm{Sn}, \mathrm{Cu}, \mathrm{Cr}, \mathrm{Hg}, \mathrm{Ni}$, Asa elements in honey samples were determined by ICP-OES instrument. The samples were digested in microwave oven using nitric acid and hydrogenperoxide. The mean concentration of elements and the lowest and highest values were determined. In the present study, $\mathrm{Cu}(11,41$ and 4,46); $\mathrm{A} 1$ (53,82 to 92,55); $\mathrm{Cr}(6,10$ to 4,52); $\mathrm{Hg}(1,92$ to 5,47$) ; \mathrm{Pb}(5,27$ to 27,96$) ; \mathrm{Sn}(502,6$ to 615,49$)$; As $(3,26$ to 17,85$)$; Ni $(3,23$ to 5,11$) \mu \mathrm{gg}-1$ levels were determined Chemical Data, It is observed that the level of heavy metal accumulation is very high along the Urban - Industrial gradient, and this is determined by comparing the different anthropogenic activities increasing the residual density of the related toxic metals and posing a risk for the health of the people living in the city. To conclude, the concentrations of detected heavy metals in collected honey samples were above the maximum residue limits of some international residue limits. Therefore it would pose a risk to human health. The fact that Şanlıurfa Province is determined by using bee products for the determination of environmental pollution and will be researched scientifically makes this study unique.
\end{abstract}

Keywords: Heavy metal, Honey, Bee, Şanlıurfa, ICP-MS

Special Issue of Health Sciences

DOI: $10.7176 /$ JSTR/6-03-25

\section{Arı Ürünlerinin Şanlıurfa İlinde Çevresel Kirlenmeye Yol Açan Toksik Ağır Metal Kalıntılarının Belirlenmesinde Biyoindikatör Olarak Kullanılması}

Özet

$\mathrm{Bu}$ çalışmada toksik ağır metal elementlerinin kalıntı seviyesini belirlemek için 45 bal örneği analizi yapıldı. Bal numunelerinin toplanacağı arı kovanları Ş.urfa merkez ilçeleri ile çevre ilçeler ( Bozova, Siverek, Harran, Bozova, Suruç) yerleştirildi. Ballardaki ağır metal konsantrasyonu ( $\mathrm{Pb}, \mathrm{Cd}, \mathrm{Al}, \mathrm{Sn}, \mathrm{Cu}$, $\mathrm{Cr}, \mathrm{Hg}, \mathrm{Ni}, \mathrm{As}$ ) en düşük ve en yüksek ppb düzeyinde ICP - MS (indüktif eşleşmiş plazma kütle spektrometresi) cihazı ile belirlendi. Mevcut çalışmada yapılan analizler sonucunda $\mathrm{Cu}(\mathbf{1 1 , 4 1}$ ile 4,46); 
Al (53,82 ile 92,55); Cr (6,10 ile 4,52); Hg (1,92 ile 5,47); Pb (5,27 ile 27,96); Sn (502,6 ile 615,49); As $\left(3,26\right.$ ile 17,85); Ni (3,23 ile 5,11) $\mu_{g g}{ }^{-1}$ düzeylerinde tespit edildi. Kimyasal veriler, Kent - Sanayi gradyanı boyunca ağır metal birikimi düzeyi çok yüksek olduğu gözlenirken bunun farklı antropojenik aktivitelerin ilgili toksik metallerin kalıntı yoğunluğunu artırdığını ve şehirde yaşayan insanların sağlı̆̆ için risk oluşturduğu ve yasal değerlerin üstünde olduğu tespit edildi. Şanlıurfa ilinin çevresel kirliliği tespiti amacıyla arı ve arı ürünlerinin kullanılarak belirlenmesi ve bilimsel olarak araştırılacak olması bu çalışmayı özgün kılmaktadır.

\section{Anahtar Kelimeler: Ağır metal, Bal, Arı, Şanlıurfa, ICP-MS}

\section{Giriş}

Kimyasal kirleticiler arasında ağır metaller ciddi biçimde toksiktirler ve canlı organizmaların bunlara (insan, hayvan ve bitki) maruz kalmaları sonucu sağlıklarını olumsuz yönde etkiler. Ağır metallerin gıda zincirinde varlığına çevre kirliliği neden olur. Ağır metallerin toprak ve su içerisine yayılması doğrudan gida zincirinde sona erer (Linden ve ark., 2003). Ve fizyolojik fonksiyonları nedeniyle inorganik kirleticiler grubunda yer alırlar (Serbula ve ark., 2013). Hızlı ve sürekli salınımları, mobilizasyon ve dispersiyon kapasiteleri, biyolojik olarak parçalanamayan ve uzun ömürlü olmaları nedeniyle, çevrede uzun süreli akümülasyon özelliğine sahiptirler (Rodriguez ve ark., 2012; Sun ve ark., 2010). As, Cd, Cr ve $\mathrm{Pb}$ gibi ağır metallere uzun süreli maruz kalmanın insan sağlığı üzerine olumsuz etki yaptığı bilinmektedir (Jaishankar ve ark., 2014).

Birçok kuruluş çeşitli faaliyetleri sonucu oluşan çevre kirliliğini kontrol altında tutmak ve önlemek amacıyla biyolojik indikatörleri kullanmayı tercih etmektedirler. Kirleticilere karşı duyarlılık gösteren ve bu kirletici maddeleri vücutlarında biriktirerek uzun süre tutabilen canlı varlıklar biyolojik indikatör olarak kullanılırlar. Bu özellikleri nedeniyle, su, hava veya toprakta doğrudan kirlenme ölçümlerinde biyoindikatörlerden yararlanılmakta ve bu canlıların popülasyon değişimleri izlenmektedir (Yılmaz N, 1996). Böcekler en tanınmış biyoindikatörlerden biridir.

Çevresel kirlenmeyi ve kirleticileri izleme amacıyla bal arılarının biyoindikatör olma ihtimali araştırılmıştır (Gutiérrezve ark., 2015; Jones, 1987). Yapılan çalışmada balda eser elementlerin çok düşük düzeyde olması nedeniyle çevre kirliliği ve kirleticilerinin izlenmesinde bal arılarının çok daha iyi bir biyoindikatör olabileceği belirtilmektedir. Arıların kovandan çok uzağa ve büyük bir alanda uçabilmesi, insanlar tarafından erişimi zor olan yerlerde genellikle $2-3 \mathrm{~km}$ çapında yüzeye yayılabilmeleri, ayrıca arıların yüksek üreme oranı, çevreye yakın temasları, toksik maddelere karşı hassas olmaları biyoindikatör olarak tercih edilmelerinde temel rol oynar. Arıların ve arı ürünlerinin özellikle hava kirliliği denetlemesinde ve çevresel kirlilik düzeyinin belirlenmesinde kullanılması dikkat çekmektedir (Girotti ve ark., 2013; Sun ve ark., 2010; Porrini ve ark., 2003; Al Naggar ve ark., 2013). Bal peteklerde depolanan tatlı bir maddedir ve binlerce yıldır insanoğlunun özel ve kaliteli olan şeyleri ifade ettiği bir kavramı içinde barındırır. Arı kolonileri için uygun olmayan konaklama koşulları ile bal işlenirken yapılan bilinçli yada bilinçsiz yanlışlıklar balın orijinal özelliklerini ve kalitesini bozmaktadır (Genç ve Dadaloğlu, 2002). Bal, balmumu veya polen gibi arı ürün analizleri, toprak, bitki ve hava kirliliğine yol açan toksik metallerin tespitinde kullanılabilir (Porrini ve ark., 2003; Al Naggar ve ark., 2013). Bunun nedeni ağır metallerin atmosferde arıların tüylü vücutlarına yapışarak ve kovana polenle taşınabilir veya çiçek nektarı ile birlikte emilebilir. Metaller balın kirlenmesine neden olabilir (Fakhimzadeh., 2000).

Arılar (hem toplayıcılar hem de alıcılar) aktif olarak nektardan ağır metalleri alabilirler (Devillers., 2002). Metal alımı ve birikimi esas olarak bitki çiçek kontaminasyonu ile ilişkilidir (Hladun ve ark., 2016). Arı ürünlerinde biyobirikim sonucu oluşan ağır metal kalıntıları şehirde yaşayan insanlar için yüksek bir maruz kalma riski taşımaktadır. Bu nedenle A. mellifera'yı biyoizleme için kullanımı çevre kirliliğini değerlendirmek için yararlı bir yöntemdir (Lambert ve ark., 2012; Bargańska ve ark., 2016).

İnsan faaliyetleri sonucunda su ve toprak gibi doğaya atılan ağır metaller insan ve hayvan sağlığı ve çevre üzerine olumsuz olarak etki etmektedir. Savaş nedeniyle çevre ülkelerden Şanlıurfa'ya fazla göç edilmesi sonucu oluşan nüfus artışı ve devlet destekleriyle hızlı gelişen sanayi faaliyetleri sonucunda hava ve çevre kirliliği ciddi oranlarda artış göstermiştir. Bu kirliliğin tespiti amacıyla bal arıları çok iyi bir biyoindikatördür. Bu çalışmamızda sanayi bölgesi, nüfusun yoğun olduğu Karaköprü merkez ilçe ve tarımsal kirlenmenin belirlenmesi için Eyyübiye ilçesine bal arısı kovanları yerleştirilerek, üretilecek olan balda kirliliğin en önemli unsuru olan ağır metallerin konsantrasyonu ( $\mathrm{Na}, \mathrm{K}, \mathrm{Ca}, \mathrm{Mn}, \mathrm{Fe}, \mathrm{Cu}, \mathrm{Zn}$, $\mathrm{Se}, \mathrm{Al}, \mathrm{Cr}, \mathrm{Ni}, \mathrm{Cd}, \mathrm{Pb}$ ) ppb (milyarda bir) düzeyinde kalıntı miktarları araştırılarak, gıdalarda bulunması gereken yasal limit miktarlarına göre normal olup olmadığı tespit edilecektir. 
Bu çalışmada sanayi bölgesi ve nüfusun yoğun olduğu Karaköprü, Haliliye, Eyyübiye merkez ilçe ve tarımsal kirlenmenin belirlenmesi için Harran, Suruç, Bozova, Akçakale ve Siverek ilçesine bal arısı kovanları yerleştirilerek, üretilecek olan balda kirliliğin en önemli unsuru olan ağır metallerin konsantrasyonu ( $\mathrm{Na}, \mathrm{K}, \mathrm{Ca}, \mathrm{Mn}, \mathrm{Fe}, \mathrm{Cu}, \mathrm{Zn}, \mathrm{Se}, \mathrm{Al}, \mathrm{Cr}, \mathrm{Ni}, \mathrm{Cd}, \mathrm{Pb}$ ) ppb (milyarda bir) düzeyinde kalıntı miktarları araştırılarak, gıdalarda bulunması gereken yasal limit miktarlarına göre normal olup olmadığı tespit edilecektir. Şanlıurfa ilinde çevresel kirliliğin tespitinde arıların kendisi ve arı ürünü olan balı biyoindikatör olarak ilk kez kullanıldığından özgün bir çalışmadır.

\section{Materyal ve Metod}

\subsection{Numune alımı}

Şanlıurfa İli Karaköprü, Eyyübiye, Haliliye Merkez İlçeleri ile Harran, Suruç, Akçakale, Bozova, Siverek'teki kovanlardan elde edilen 45 adet bal numunesi topland1. Ballardan 200 gr. polietilen bir kap içerisine alınarak $20-21^{\circ} \mathrm{C}$ de analiz için bekletildi.

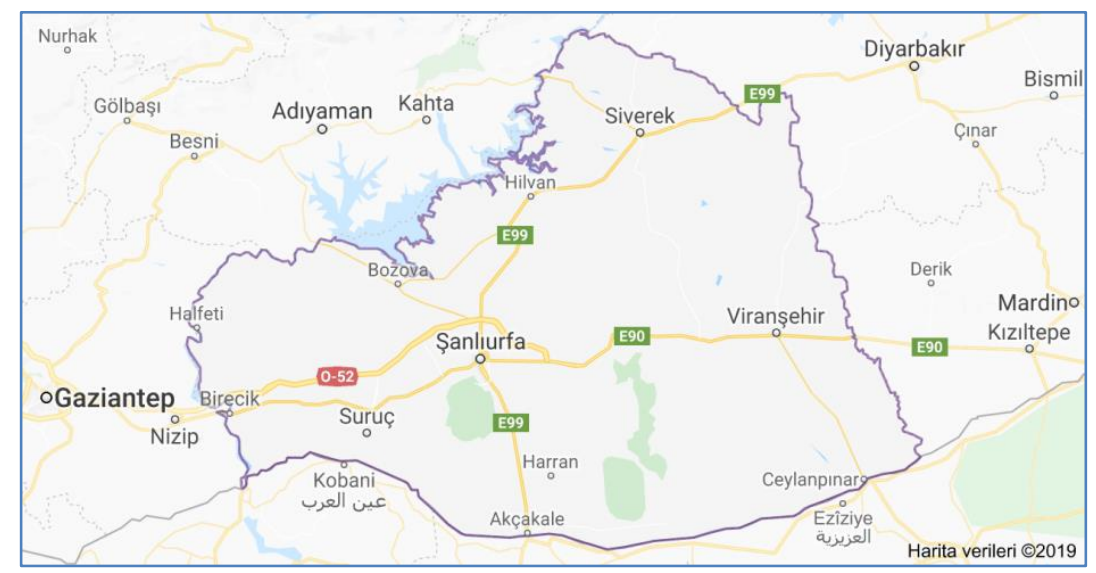

Şekil 1. Çalışma alanı istasyonları

\subsection{Bal numunelerini hazırlama ve ICP-OES Numune analizi}

Elementlerin konsantrasyonu ppb düzeyinde ( $\mathrm{Na}, \mathrm{K}, \mathrm{Ca}, \mathrm{Mn}, \mathrm{Fe}, \mathrm{Cu}, \mathrm{Zn}, \mathrm{Se}, \mathrm{Al}, \mathrm{Cr}, \mathrm{Ni}, \mathrm{Cd}, \mathrm{Pb}$ ) tespit edildi. Ekstraksiyon işlemi Yücel ve Sultanoğlu (2013) tarafindan önerilen yönteme göre gerçekleştirilmiş ve ölçümler endüktif olarak eşleşmiş plazma optik emisyon spektrometrisinde (ICP OES, Spectroblue, Almanya) gerçekleştirilmiştir.

Buna göre, her bir örnekleme alanından 5 bal örneği alındı ve kristalleşmeyi önlemek için sterilize edilmiş tüplere aktarıldı. Örnekler, bal örneklerini homojenize etmek için bir süre $70{ }^{\circ} \mathrm{C}$ olan su tankına (NÜVE ST 30, Türkiye) alınmıştır. Bu numunelerden 0,5 g bal ve bal arıları alınmıştır, daha sonra $9 \mathrm{ml}$ (HN03) \% 65 nitrik asit ve $1 \mathrm{ml} \% 30$ hidrojen peroksit eklenmiştir. Numuneler bir mikrodalga cihazında (CEM MARS 6 Sistemi 240/50, ABD) yakıldı. Mikrodalga cihazının çalışma koşulları Tablo l'de verilmiştir.

Yakılan örnekler, $5 \mathrm{ml}$ saf su ile alt-çözündürüldü. Hazırlanan kör (Blank) numuneler aynı işlemle uyguland1.

Ana stok çözeltisi (1000 mg/L) alüminyum (Al), baryum (Ba), kalsiyum (Ca), kadmiyum (Cd) dahil ICP Çok Elementli standart çözelti IV'ten (Merck Millipore, 111355, Darmstadt, Almanya) hazırlandı. Kobalt $(\mathrm{Co}), \operatorname{krom}(\mathrm{Cr})$, bakır $(\mathrm{Cu})$, demir $(\mathrm{Fe})$, potasyum $(\mathrm{K})$, magnezyum $(\mathrm{Mg})$, manganez $(\mathrm{Mn})$, sodyum $(\mathrm{Na})$, nikel $(\mathrm{Ni})$, kurşun $(\mathrm{Pb})$ ve sitrik asit ile seyreltilmiş Stronsiyum $(\mathrm{Sr})$ ve Çinko $(\mathrm{Zn})$. Bu ana stok çözeltisinden $\mathrm{Ba}, \mathrm{Fe}, \mathrm{Mg}, \mathrm{Na}$, Ni ve diğerleri için 0 , 125, 250, 500, 1000, 2500, $5000 \mathrm{ug} / \mathrm{L}$ ve diğerleri için 0, 10, 20, 50, 100, 200, 500, 1000 ug/L. Baldaki metal seviyeleri, Harran Üniversitesi Bilimsel ve Teknolojik Araştırmalar ve Uygulamalar Merkezi'ndeki ICP-OES cihazı ile gerçekleştirildi. Cihaz hazırlanan kalibrasyon standartlarıyla kalibre edildi. ICP-OES cihazının çalışma koşulları Tablo 2'de verilmiştir. 
Tablo 1. Mikrodalga çalışma koşulları

\begin{tabular}{|c|l|l|}
\hline Sicaklık derecesi & Güç & Süre \\
\hline At $70^{\circ} \mathrm{C}$ & $400 \mathrm{~W}$ & $5 \mathrm{~min}$. \\
\hline At $100^{\circ} \mathrm{C}$ & $800 \mathrm{~W}$ & $5 \mathrm{~min}$. \\
\hline At $150^{\circ} \mathrm{C}$ & $800 \mathrm{~W}$ & $10 \mathrm{~min}$. \\
\hline At $200^{\circ} \mathrm{C}$ & $800 \mathrm{~W}$ & $10 \mathrm{~min}$. \\
\hline Ventilation & & $10 \mathrm{~min}$. \\
\hline
\end{tabular}

Tablo2: ICP-OES çalışma koşulları

\begin{tabular}{|l|}
\hline PlasmaPower: $1430 \mathrm{~W}$ Coolant \\
\hline Flow: $13 \mathrm{~L} /$ minute \\
\hline NebulizerFlow: $0,75 \mathrm{~L} /$ minute \\
\hline PumpSpeed: $30 \mathrm{rpm}$ \\
\hline AuxiliaryFlow: $0,80 \mathrm{~L} /$ minute \\
\hline
\end{tabular}

\section{Bulgular ve Tartıșma}

Mevcut çalışmada Cu, Harran'da en yüksek $(11,41)$, Eyyübiye'de en düşük $(4,46)$; Al, Akçakale'de en yüksek $(92,55)$, Karaköprü'de en düşük $(53,82)$; Cr, Akçakale'de en yüksek $(6,10)$, Karaköprü'de en düşük (4,52); Hg, Haliliye'de en yüksek $(5,47)$, Akçakale'de en düşük (1,92); Pb, Eyyübiye'de en yüksek $(27,96)$, Harran'da en düşük $(5,27)$; Sn, Hilvan'da en yüksek $(615,49)$, Akçakale'de en düşük $(502,6)$; As, Eyyübiye'de en yüksek $(17,85)$, Akçakale'de en düşük $(3,26)$; Ni, Bozova'da en yüksek $(5,11)$, Akçakale'de en düşük $(3,23)$ bulundu (Tablo 1).

Tespit edilen $\mathrm{Cu}$ ve $\mathrm{Pb}$ değeri normal yasal (WHO-FAO, 2015) değerlerden daha yüksek (Tablo 4), As ve $\mathrm{Pb}$ değerleri Avrupa Birliği Kodeks ve Standartları Yönetmeliğinde belirtilen kabul edilebilir değerlerden daha yüksek bulunmuştur.

Tablo 3. Çalışma alanındaki istasyonlardan alınan homojenize numunelerde ( bal ve bal arısı) tespit edilen ağır metal düzeyleri $\left(\mu \mathrm{gg}^{-1}\right)$

\begin{tabular}{|l|l|l|l|l|l|l|l|l|l|l|l|}
\hline & & $\begin{array}{l}\text { Bal } \\
\text { cinsi }\end{array}$ & $\mathrm{Cu}$ & $\mathrm{Al}$ & $\mathrm{Cd}$ & $\mathrm{Cr}$ & $\mathrm{Hg}$ & $\mathrm{Pb}$ & $\mathrm{Sn}$ & $\mathrm{As}$ & $\mathrm{Ni}$ \\
\hline Lokalizasyon & & Blank & 9,46 & 4,01 & 0,00 & 5,86 & 1,58 & 2,16 & 473,90 & 7,79 & 1,82 \\
\hline Akçakale & 5 & Pamuk & 9,61 & 92,55 & 0,00 & 6,10 & 1,92 & 7,21 & 502,26 & 3,26 & 3,23 \\
\hline Bozova & 5 & Pamuk & 8,61 & 68,42 & 0,00 & 6,10 & 3,25 & 15,55 & 606,64 & 7,15 & 5,11 \\
\hline Hilvan & 5 & Pamuk & 10,97 & 55,41 & 0,00 & 5,59 & 2,30 & 12,16 & 615,49 & 5,04 & 4,21 \\
\hline Harran & 5 & Pamuk & 11,41 & 62,03 & 0,00 & 5,98 & 2,95 & 5,27 & 588,68 & 10,46 & 4,40 \\
\hline Suruç & 5 & Pamuk & 9,65 & 67,17 & 0,00 & 5,70 & 2,52 & 0,00 & 562,23 & 5,68 & 4,01 \\
\hline Siverek & 5 & Pamuk & 8,83 & 62,82 & 0,00 & 4,69 & 2,85 & 12,03 & 552,43 & 14,21 & 3,59 \\
\hline Haliliye & 5 & Ciçek & 8,15 & 61,79 & 0,00 & 5,60 & 5,47 & 17,59 & 539,61 & 16,05 & 3,93 \\
\hline Karaköprü & 5 & Ççek & 6,33 & 53,82 & 0,00 & 4,52 & 4,34 & 20,58 & 543,00 & 15,17 & 3,36 \\
\hline Eyyübiye & 5 & Çiçek & 4,46 & 92,53 & 0,00 & 4,82 & 5,46 & 27,96 & 543,76 & 17,85 & 3,35 \\
\hline & & Min & 4,46 & 53,82 & & 4,52 & 1,92 & 5,27 & 502,26 & 3,26 & 3,23 \\
& & Max & 11,41 & 92,55 & & 6,1 & 5,47 & 27,96 & 615,49 & 17,85 & 5,11 \\
& & Ort & 7,82 & 61,65 & & 4,91 & 3,10 & 11,83 & 505,41 & 9,48 & 3,51 \\
\hline
\end{tabular}


Tablo 4. Dünya Sağlık Örgütü (WHO-FAO) tarafindan nektarlar ve meyve suları gibi gıdalarda bulunabilecek maksimum element düzeyleri $\left(\mu \mathrm{gg}^{-1}\right)$ (Anonim, 2005)

\begin{tabular}{|lcc|}
\hline Element & Maksimum düzey $(\mu \mathbf{g g}-1)$ & Mevcut Çalışma \\
\hline $\mathrm{Cd}$ & 0.03 & 0 \\
\hline $\mathrm{Pb}$ & 0.3 & 11,83 \\
\hline $\mathrm{Fe}$ & 15 & 7,82 \\
\hline $\mathrm{Cu}$ & 5 & \\
\hline $\mathrm{Zn}$ & 5 & \\
\hline
\end{tabular}

Avrupa Birliği Kodeks ve Standartları Yönetmeliği (2009) tarafından kabul edilen nektarlar ve meyve suları gibi gıdalarda bulunabilecek maksimum element düzeyleri; Pb miktarı 0.05 ppm., Cd miktarı 0.05 ppm. şeklindedir.

Biyoizleme, çevresel izleme için hızlı, kolay ve en ucuz yoldur. Bal arıları ve kovan matrisleri gösterge olarak kullanılır. Bal arıları en iyi karasal çevre kirliliği göstergelerinden biridir, çünkü çok hassastır ve çevre ile doğrudan temas halindedir. Arı kovanı portatiftir ve bitki örtüsü ve arı ürünü olmasa bile bölgeden gerçek numuneleri toplama firsatı verir. Mevcut çalışma küçük ölçekte gerçekleştirildi. Bal arılarındaki makro ve mikro elementlerin içeriği geniş aralıklarda değişir ve arı kovanı alanı (toprak türleri ve Nektar kaynak tesisi dahil) ve ekolojik durumu, arı kolonilerini yetiştirme yöntemi (ek besleme dahil), işçi arıların yaşı, arı türlerinin ve arı kolonilerinin fizyolojik ve sağlık durumları, vb. gibi faktörlere bağlıdır (Zhelyazkova, 2012).

İzmir'de yapılan bir çalışmada sanayi bölgesine yakın beş farklı noktadan bal arıları, propolis ve çam ağaçları çevrenin zehirli metal kirliliği için biyolojik göstergeler olarak kullanılmış. Çalışma sonucunda örneklerde kadmiyum, kurşun, arsenik ve civa içeren ağır metaller tespit edilirken, analiz edilen tüm örneklerde civa bulunamamıştır (Şerifoğlu, 1993).

Mevcut çalışmada kadmiyum tespit edilemezken, Civa 1,92 ile 5,47 $\mu \mathrm{gg}^{-1}$ konsantrasyonu arasında gözlendi. Civa ağır metali tespit edilmesinin nedeni, bölgede sanayi atmosferik cıva kirliliği kaynaklarının yakınında bulunmasının bir sonucu olabilir, bu nedenle bal arıları izleme süresi boyunca cıvaya maruz kalmış olabilir (Matin ve ark., 2016).

Yapılan başka bir çalışmada, Kayseri'nin farklı bölgelerinden toplanan 26 farklı bal örneğinde Cd 0,09 ile $0,24 \mu \mathrm{gg}^{-1}, \mathrm{Cu} 0,01$ ile $0,72 \mu \mathrm{gg}^{-1}$, Zn 1,29 ile 5,39 $\mu \mathrm{gg}^{-1}$, Ni 0,03 ile 1,43 $\mathrm{ggg}^{-1}, \mathrm{~Pb} 0,02$ ile $1,50 \mu \mathrm{gg}^{-}$ ${ }^{1}$, Cr 0,09 ile $1,89 \mu \mathrm{gg}^{-1}$, Mn 0,02 ile $1,56 \mu \mathrm{gg}^{-1}$, Fe 0,57 ile 8,74 $\mu \mathrm{gg}^{-1}$ ve Se 0,006 ile $0,58 \mu \mathrm{gg}^{-1}$ konsantrasyonu arasında olduğu gözlendiği tespit edilmiş (Leblebici, 2006).

$\mathrm{Bu}$ çalışmada $\mathrm{Cu}, \mathrm{Ni}, \mathrm{Pb}, \mathrm{Cr}$ önemli derecede yüksek bulunmuştur (4,36-11,41; 3,23-5,11; 5,27-27,96; 4,52-6,10 $\left.\mathrm{ggg}^{-1}\right)$ Cr konsantrasyonunun yüksek çıkmasının en önemli sebebi olarak yola çok yakın olması gösterilebilir. Cr kirlenmesine neden olan en önemli etmenler, atıklar, metal işlemciliği, plastikler olarak gösterilmektedir. Cu kirlenmesine neden olan en önemli kaynaklar hayvansal gübreler, pestisitler, lağım, küller ve demir, çelik endüstrisi gösterilmektedir (Markert, 1993). Zirai ilaçlama için kullanılan fungisit, herbisit ve insektisit gibi kimyasal gübreler de toprakta bir takım bulaşma ve kirlenmelere neden olabilmektedir. CuSO4 asmalarda ve çeşitli tarımsal ürünlerde fungisit olarak kullanılmaktadır (Şerifoğlu 1993).

Burada $\mathrm{Pb}$ konsantrasyonunun yüksek çıkmasının en büyük sebebi yol kenarına yakın olması nedeniyle taşıtlar ve atıklar olarak düşünülebilir. Kurşun sonuçları bakımından bal örneklerimizin ağır metal kirlenmesine uğradığı ve kirlenmenin yol kenarına ve şehir içine yakın alanlarda daha yoğun olduğu gözlenmektedir. $\mathrm{Pb}$ kirlenmesine neden olan en önemli kaynaklar; metal işletmeciliği, rafineri, taşıtlar, fosil yakıtlar ve atıklardır (Şerifoğlu, 1993).

\section{Sonuç}

Ağır metal kirliliğinin insan sağlığı üzerinde olumsuz etkileri vardır. Günümüzde endüstriyel çalışma hayatında, insanlar bu kirletici maddelere, bulaşmış gıdaların solunması ve tüketilmesi yoluyla maruz kalmaktadır. Bu nedenle, kendileri veya (bu durumda bal, propolis, polen vb.) bal arısı ürünleri gibi göstergeleri kullanmak çevresel etkiler hakkında farkındalık yaratabilir.

Yerleşim bölgelerine yakın noktalara yerleştirilen kovanlardaki ballar, evsel, endüstriyel ve trafik kökenli kirleticilere maruz kalabilmektedir. Bu nedenle Şanlıurfa ilinde arıcılık faaliyetlerinin kirlenme tehdidi 
altında bulunan; yol kenarları, sanayi ve endüstri kuruluşları, şehir merkezi, yoğun tarım alanları ve kirlenmiş su kenarları gibi alanlarda yapılmamasına özen gösterilmeli, ayrıca, ağır metal içermeyen arıcılık ilaçları kullanılmalıdır.

\section{Kaynaklar}

Al Naggar, Y. A., Naiem, E. A., Seif, A. I., Mona, M. H., 2013. Honey bees and their products as a bio-indicator of environmental pollution with heavy metals. Mellifera, 13, 10-20.

Anonymous, Codex Alimentarius Commission Joint FAO/WHO, Food Standards Programme Recommended European-Regional Standard for Honey, 2005.

Anonymous, AIJN. European Fruit Juice Association, Regional Workshop On Fruit and Vegetable Processing in The EU, Practical consequences of implementation of EU legislation and Codex standards applicable to juices, Serbia, 2009.

Bargańska Ż, Ślebioda M, Namieśnik J., 2016. Honey bees and their products-bioindicators of environmental contamination. Crit Rev Environ Sci Technol 46(3): 235-248

Fakhimzadeh, K., 2000. Honey, polen and bees as indicator of metal pollution. Acta Universitat is Carolinae Environmentalica, 14, 13-20.

Finger, D., Filho, I.K., Torres, Y.R., Quina'1ia, S.P., 2014. Propolis as an indicator of environmental contamination by metals. Bull. Environ. Contam. Toxicol. 92, 259-264

Devillers, J.,2002. The ecological importance of honey bees and their relevance to ecotoxicology. In J. Devillers and M.-H. Pham-Delegue (Eds.), Honey bees: estimating the environmental impact of chemicals (pp. 1-11). CRC Press 2002. DOI: https://doi.org/10.1201/9780203218655.ch11

Genç, F., Dadoloğlu, A., 2002. Arıcılığın Temel Esasları, Atatürk Ü. Ziraat Ofset Tesisi, s.233, Erzurum.

Gutiérrez, M., Molero, R., Gaju, M., van der Steen, J., Porrini, C.,Ruiz, J. A., 2015. Assessment of heavy metal pollution in Córdoba (Spain) by biomonitoring for aging honey bee Environmental Monitoring and Assessment, 187(10), 651.https://doi.org/10.1007/s10661-015-4877-8

Han, P., Niu, C., Lei, C., Cui, J., Desneux, N., 2010. Quantification of toxins in a Cry 1 Ac + Cpti cotton cultivar and its potential effects on the honey bee Apis mellifera L. Ecotoxicology 19, $1452-1459$

Hladun KR, Di N, Liu T-X, Trumble JT., 2016. Metal contaminant accumulation in the hive: consequences for whole-colony health and brood production in the honey bee (Apis mellifera L.). Environ Toxicol Chem 35: 322-329

Jaishankar M, Tseten T, Anbalagan N, Mathew BB, Beeregowda KN.,2014. Toxicity, mechanism and health effects of some heavy metals. Interdiscip Toxicol 7(2): 60-72.

Jones, K.C., 1987. Honey as an Indicator of Heavy Metal Contamination, Water-Air, and Soil Pollution. 33, 179-189.

Lambert O, Piroux M, Puyo S, Thorin C, Larhantec M, DelbacF, Pouliquen H., 2012. Bees, honey and pollen as sentinels for lead environmental contamination. Environ Pollut 170: 254-259

Leblebici Z., 2006. Kayseri Yöresinde Bulunan Bazı Bal Örneklerinde Ağır Metal Kirliliğinin Belirlenmesi. Erciyes Üniversitesi, Fen Bilimleri Enstitüsü Yüksek Lisans Tezi Kayseri 
Linden, A., Olsson, M., Bensryd, I., Lundh, T., Skerfving, S., Oskarssona, A., 2003. Monitoring of cadmium in the chain from soil via crops and feed to pig blood and kidney. Ecotoxicology and Environmental Safety, 55(2), 213-222. https://doi.org/10.1016/S0147-6513(02)00079-9

Matin, G., Kargar, N., ve Buyukisik, H. B., 2016. Bio-monitoring of cadmium, lead, arsenic and mercury in industrial districts of Izmir, Turkey by using honey bees, propolis and pine tree leaves. Ecological Engineering, 90, 331-335.

Markert, B., Plants as Biomonitors Indicators for Heavy Metals in the Terrestrial Environment, VCH Publisher, Weinheim, 1993.

Porrini, C., Sabatini, A. G., Girotti, S., Ghini, S., Medrzycki, P., Grillenzoni, F., Bortolotti, L., Gattavecchia, E., Celli, G., 2003. Honey bees and bee products as monitors of the environmental contamination. Apiacta, 38, 63-70.

Rodriguez, J.H., Wannaz, E.D., Salazar, M.J., Pignata, M.L., Fangmeier, A., Franzaring, J., 2012. Accumulation of polycyclic aromatic hydrocarbons and heavy metals in the tree foliage of Eucalyptus rostrata, Pinus radiata and Populous hybridus in the vicinity of a large aluminium smelter in Argentina. Atmos. Environ. 55, 35e42

Serbula, S.M., Kalinovic, T.S., Ilic, A.A., Kalinovic, J.V., Steharnik, M.M., 2013. Assess-ment of airborne heavy metal pollution using Pinus spp. And Tilia spp. Aerosol Air Qual. Res. 13, 563573.

Sun, F., Wen, D., Kuang, Y., Li, J., Li, J., Zuo, W., 2010. Concentrations of heavy metals and polycyclic aromatic hydrocarbons in needles of Masson pine (Pinus mas-soniana L.) growing nearby different industrial sources. J. Environ. Sci. 22 (7), 1006-1013.

Şerifoğlu, G.A., Ege bölgesi ballarının bazı ağır metal birikimlerinin saptanması, Doktora Tezi, E.Ü. Fen. Bil. Ens., İzmir, 1993

Yılmaz, N., 1996. İzmit yöresinden toplanan bal ve polen örneklerinde element analizi ile bal örneklerinde polen analizi, Bilim Uzmanlığı Tezi, Hacettepe Üniversitesi, Ankara.

Zhelyazkova, I., 2012. Honey bees bioindicators for environmental quality. Bulg. J. Agric. Sci. 18 (No 3), 435-442 